\title{
Preheated Carbon Source for Carbon Nanotube Synthesis
}

\author{
C.Y. Liu ${ }^{1}$, N. K. Chang ${ }^{1}$, Y. T. Chang ${ }^{1}$, J. H. Hsu ${ }^{1}$, S. H. Chang ${ }^{1,2}$ \\ ${ }^{1}$ Department of Mechanical Engineering National Taiwan University, Taiwan, ROC, d92522010@ntu.edu.tw \\ ${ }^{2}$ Mechanical and Systems Research Laboratories Industrial Technology Research Institute, Taiwan, ROC, shuochang@itri.org.tw
}

\begin{abstract}
In this paper, we synthesized single-walled carbon nanotubes (SWCNTs) using chemical vapor deposition (CVD) process in a furnace with three different heating regions. Ferritin nanoparticles were used as catalyst for the CNTs synthesis through carbon source which are methane and ethylene mixture. The reason we used a three stage furnace is to preheat the carbon source at higher temperatures and to synthesize CNTs at lower temperatures. This method can be effective to grow SWNTs at lower temperature. Furnace temperature, methane flow, productivity of CNTs and the diameter distributions of CNTs were considered in the process of CNTs synthesis. The lowest synthesis temperature of CNTs grown from ferritin nanoparticles was $700^{\circ} \mathrm{C}$. In the future, it is possible to apply this method to grow CNTs on electronic devices at the lower temperature.
\end{abstract}

Keywords: carbon nanotubes, nanoparticles, CVD, synthesis temperature,

\section{Introduction}

Carbon nanotubes (CNTs) were discovered by Iijima in 1991 [1], carbon nanotubes have been intensively studied in chemistry, physics, and materials science. Numerous methods to grow CNTs have been developed, including arc discharge, chemical vapor deposition, pulsed laser ablation and so on [2-4]. Chemical vapor depositions (CVD) of SWNTs has been proved to be a classic method to produce SWNTs. Compared to the arc discharge and laser ablation methods, CVD could offer more control over the growth temperature, catalyst composition, feeding gas, and other parameters [5-7].

There were already a few reports on carbon nanotube growth utilizing ferritin as a catalyst. Zhang et al. dispersed iron oxide nanoparticles produced from apoferritin on a mesoporous alumina support and synthesized single-walled carbon nanotubes (SWNTs) at $900^{\circ} \mathrm{C}$ [8]. Diameter-controlled growth of MWNTs has been achieved by CVD with ferrtin by Daiyu et al. [9].

In this paper, we report on the single-wall carbon nanotube synthesis on a silicon oxide substrate using ferritin as a catalyst by chemical vaper deposition process in a furnace with three different heating regions at a temperature as low as $700^{\circ} \mathrm{C}$.

\section{Experimental}

A CVD set-up equipped with a 1 inch quartz tube furnace was used. In the CVD, three heating zones in the furnace can be individually controlled to heat up. The catalyst we used was ferritin consisting of a protein shell and iron particles [10]. Concentration of the ferritin solution was controlled to $0.5 \mathrm{~g} / \mathrm{L}$ by deionized water dilution. Silicon wafers with $500 \mathrm{~nm}$ thermal oxide layer were used as substrates. Then, the substrates were placed on a flat quartz board and inserted into the three positions of a 1 inch diameter quartz tube into the CVD furnace, as show in Figure 1.1(a). The furnace was heated up to $950^{\circ} \mathrm{C}$, $850^{\circ} \mathrm{C}$, and $750^{\circ} \mathrm{C}$ in 50 minutes. Growing nanotubes on the substrate took place for 10 minutes under combined flows of $500 \mathrm{sccm}$ of $\mathrm{H}_{2}, 20 \mathrm{sccm}$ of $\mathrm{C}_{2} \mathrm{H}_{4}$ and 62-1000 sccm of $\mathrm{CH}_{4}$. The region at $950^{\circ} \mathrm{C}$ was a preheating zone, $850^{\circ} \mathrm{C}$ was a transition zone and $750^{\circ} \mathrm{C}$ was a growth zone, as show in Figure 1.1(b).

The diameters of the ferritins, nanoparticles, and nanotubes were mainly determined with an Atomic Force Microscope (AFM) in the tapping mode. High-resolution transmission electron microscopy (HR-TEM; 2100F, JEOL) and scanning electron microscopy (SEM; ERA 8800 , Elionix) were used to characterize the carbon nanotubes.

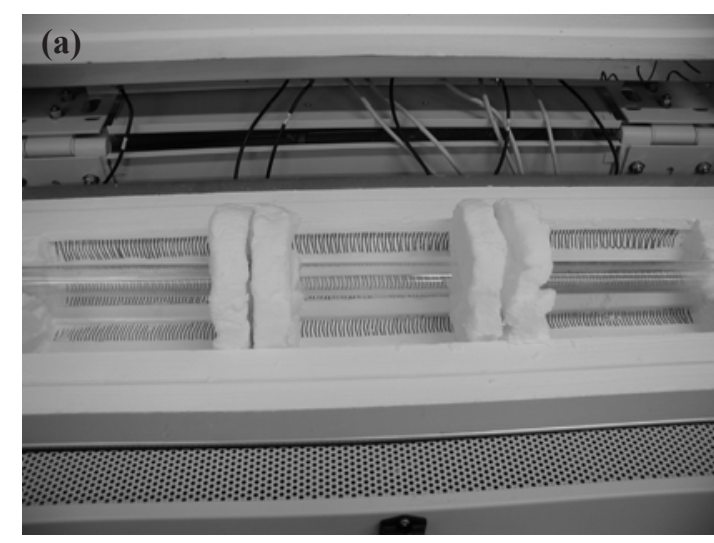

(b)

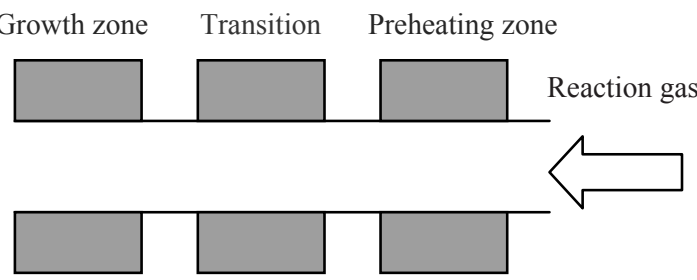

Figure 1.1. (a) The form of the CVD furnace; (b) Sketch of the three-segment CVD. 


\section{Results and Discussion}

An AFM image of ferritin on a silicon substrate is shown in Figure 1.2. The diameter of ferritin is about $12 \mathrm{~nm}$. It can be seen in the image that the ferritin molecules are uniformly distributed on the substrate. After nanotube growth, we scanned 20 different areas (unit area $10 \mu \mathrm{m} \times$ $10 \mu \mathrm{m})$ on the substrate by AFM and recorded the counts, lengths and diameters of nanotubes. We defined the productivity of nanotubes as the total length of nanotubes per unit area. The counts of nanotubes synthesized at $950^{\circ} \mathrm{C}$ and $850^{\circ} \mathrm{C}$, under the flow rate of $500 \mathrm{sccm}$ of $\mathrm{H}_{2}$, $20 \mathrm{sccm}$ of $\mathrm{C}_{2} \mathrm{H}_{4}$ and $62-1000 \mathrm{sccm}$ of $\mathrm{CH}_{4}$, are as listed in Table 1.1. The productivity of SWNTs per $100 \mu \mathrm{m}^{2}$ at $950^{\circ} \mathrm{C}$ and $850^{\circ} \mathrm{C}$ are shown in Figure 1.3. The optimal productivity of SWNTs was obtained when the $500 \mathrm{sccm}$ of $\mathrm{CH}_{4}$ at $950^{\circ} \mathrm{C}$ and $250 \mathrm{sccm}$ of $\mathrm{CH}_{4}$ at $850^{\circ} \mathrm{C}$ were conducted, respectively. Figure 1.4 shows the diameter distribution of SWNTs grown at $950^{\circ} \mathrm{C}$ and $850^{\circ} \mathrm{C}$. The SEM images of the diameters of SWNTs were $3.2 \mathrm{~nm}$ and $3.8 \mathrm{~nm}$ at $950^{\circ} \mathrm{C}$ and $850^{\circ} \mathrm{C}$, respectively, as shown in Figure 1.5.

Few SWNTs were grown at $750^{\circ} \mathrm{C}$, which was controlled by the catalyst of ferritin only when the flow rate with $\mathrm{CH}_{4}$ of $250 \mathrm{sccm}, \mathrm{C}_{2} \mathrm{H}_{4}$ of $20 \mathrm{sccm}$ and $\mathrm{H}_{2}$ of $500 \mathrm{sccm}$. The diameters of SWNTs were $0.85 \sim 3.3 \mathrm{~nm}$ and the length was about $1 \sim 5 \mu \mathrm{m}$, as shown in Figure 1.6. The productivity of SWNTs at $700^{\circ} \mathrm{C}$ was less than that at $750^{\circ} \mathrm{C}$ only when the flow rate was controlled with $\mathrm{CH}_{4}$ of $125 \mathrm{sccm}, \mathrm{C}_{2} \mathrm{H}_{4}$ of $20 \mathrm{sccm}$ and $\mathrm{H}_{2}$ of $500 \mathrm{sccm}$. The diameters of SWNTs were $0.9 \sim 2.2 \mathrm{~nm}$ and the length about $2 \sim 5 \mu \mathrm{m}$, as shown in Figure 1.7.

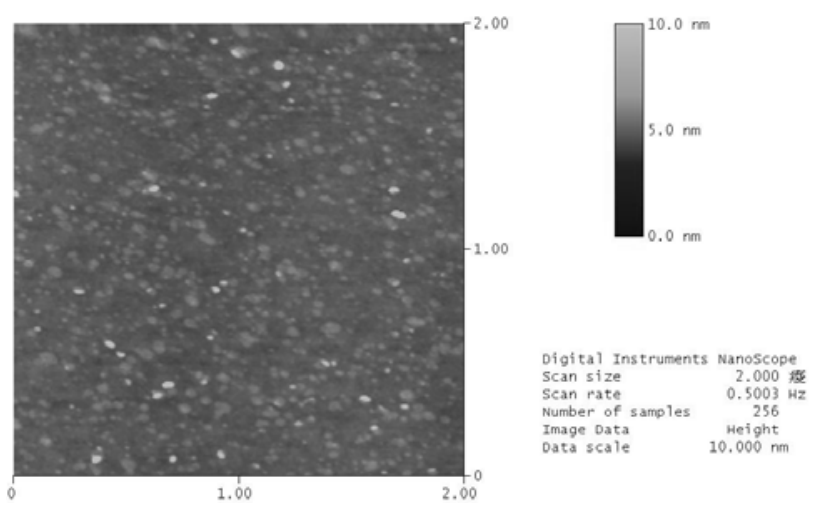

Figure 1.2. AFM image of the concentrations of the ferritin solutions were controlled to $0.5 \mathrm{~g} / \mathrm{L}$ by deionized water dilution.

Table 1.1. The counts of nanotubes at different flow rate on $\mathrm{CH}_{4}$ $\left(\mathrm{H}_{2}: 500 \mathrm{sccm}, \mathrm{C}_{2} \mathrm{H}_{4}: 20 \mathrm{sccm}\right)$

\begin{tabular}{|c|c|c|c|c|c|c|}
\hline $\mathrm{CH}_{4}(\mathrm{sccm})$ & 1000 & 750 & 500 & 250 & 125 & 62 \\
\hline $\begin{array}{l}\text { The counts of } \\
\mathrm{CNT} \text { per } 100 \\
\mu \mathrm{m}^{2} \text { at } 950^{\circ} \mathrm{C}\end{array}$ & 3 & 1 & 10 & 6 & 2 & 0 \\
\hline $\begin{array}{l}\text { The counts of } \\
\mathrm{CNTs} \text { per } 100 \\
\mu \mathrm{m}^{2} \text { at } 850^{\circ} \mathrm{C}\end{array}$ & 1 & 2 & 4 & 8 & 3 & 1 \\
\hline
\end{tabular}
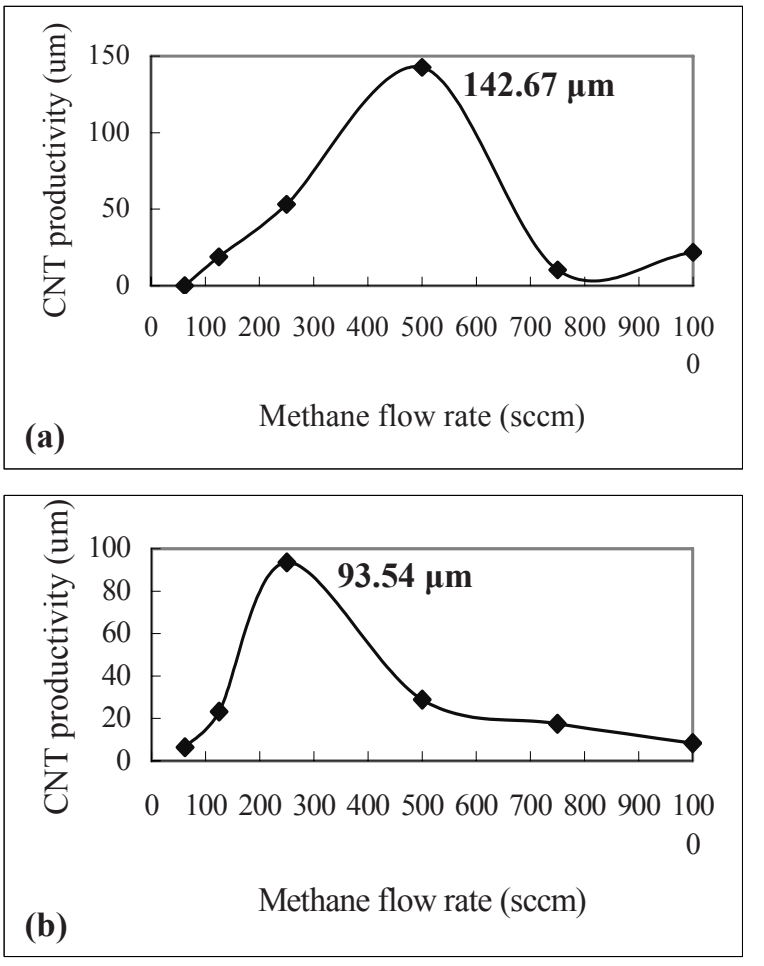

Figure 1.3. The productivity of carbon nanotubes per $100 \mu \mathrm{m}^{2}$, (a) $950^{\circ} \mathrm{C}$ (b) $850^{\circ} \mathrm{C}\left(\mathrm{H}_{2}: 500 \mathrm{sccm}, \mathrm{C}_{2} \mathrm{H}_{4}: 20 \mathrm{sccm}\right.$ and $\mathrm{CH}_{4}: 62-$ $1000 \mathrm{sccm}$ )
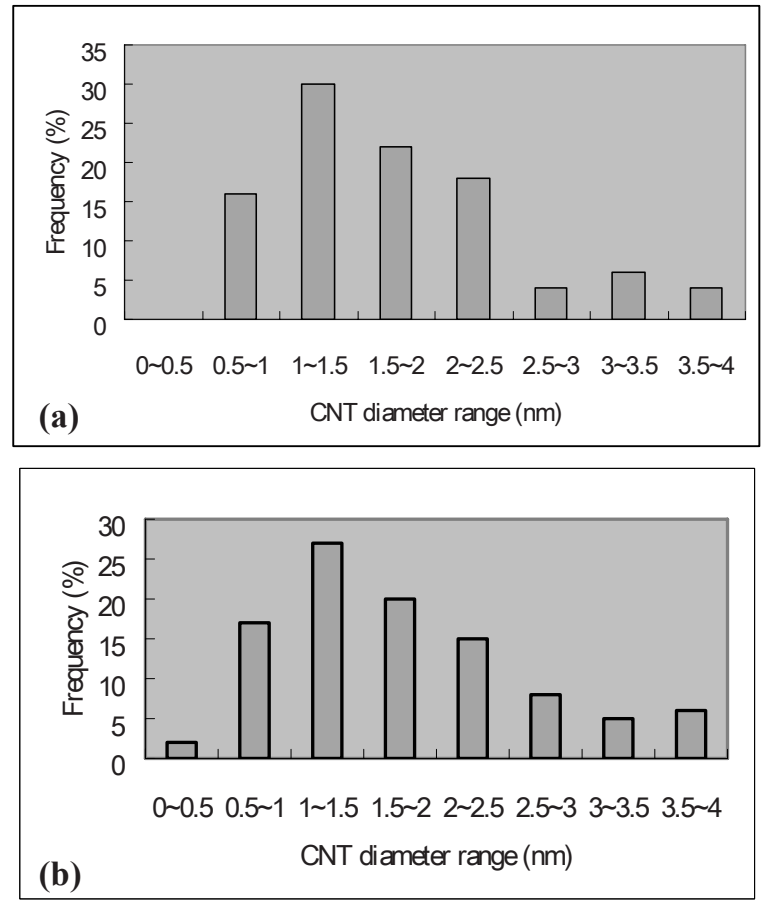

Figure 1.4. Diameter distribution of carbon nanotubes grown at (a) $950{ }^{\circ} \mathrm{C}$ (b) $850^{\circ} \mathrm{C}$. 

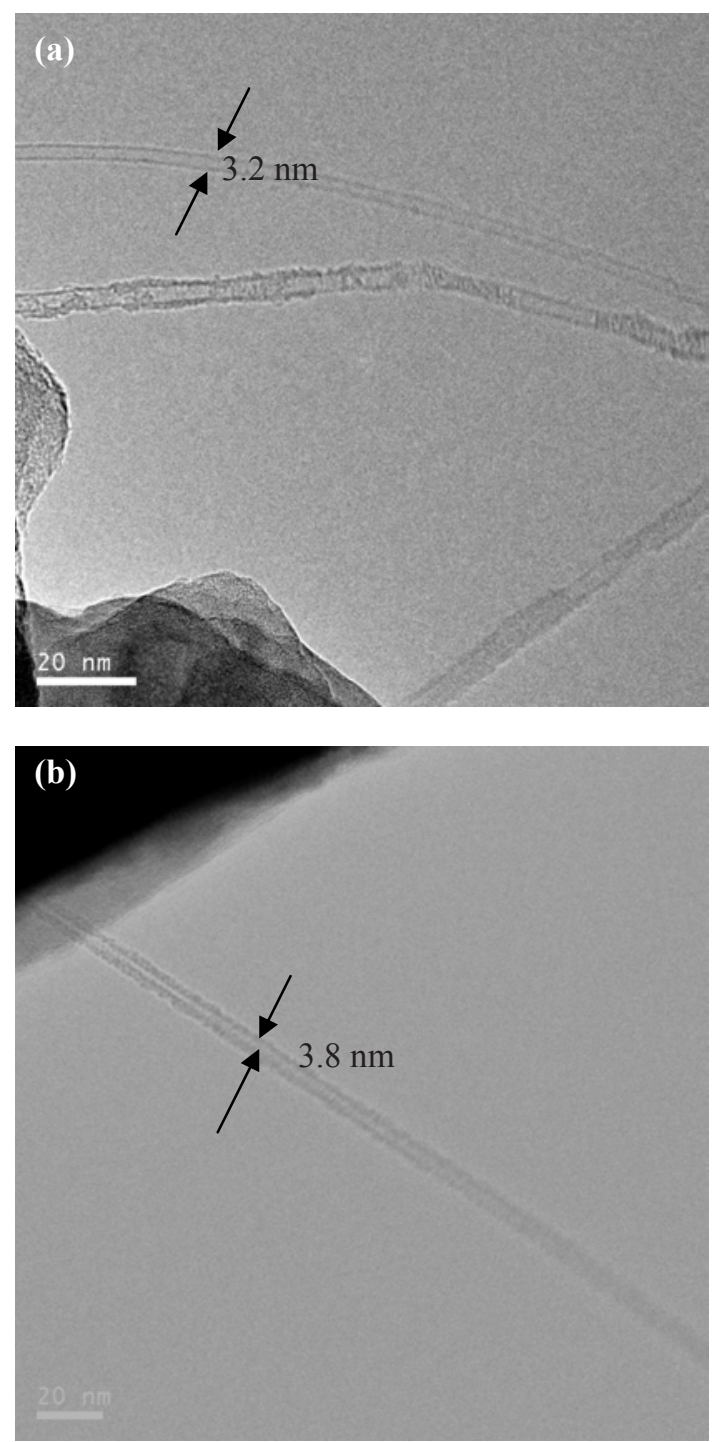

Figure 1.5. TEM images of carbon nanotubes grown at (a) $950^{\circ} \mathrm{C}$ (b) $850^{\circ} \mathrm{C}$
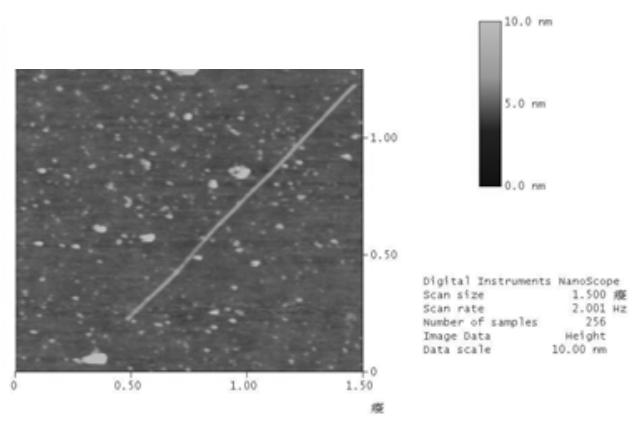

Figure 1.6. The AFM image of SWNT at $750^{\circ} \mathrm{C}$.
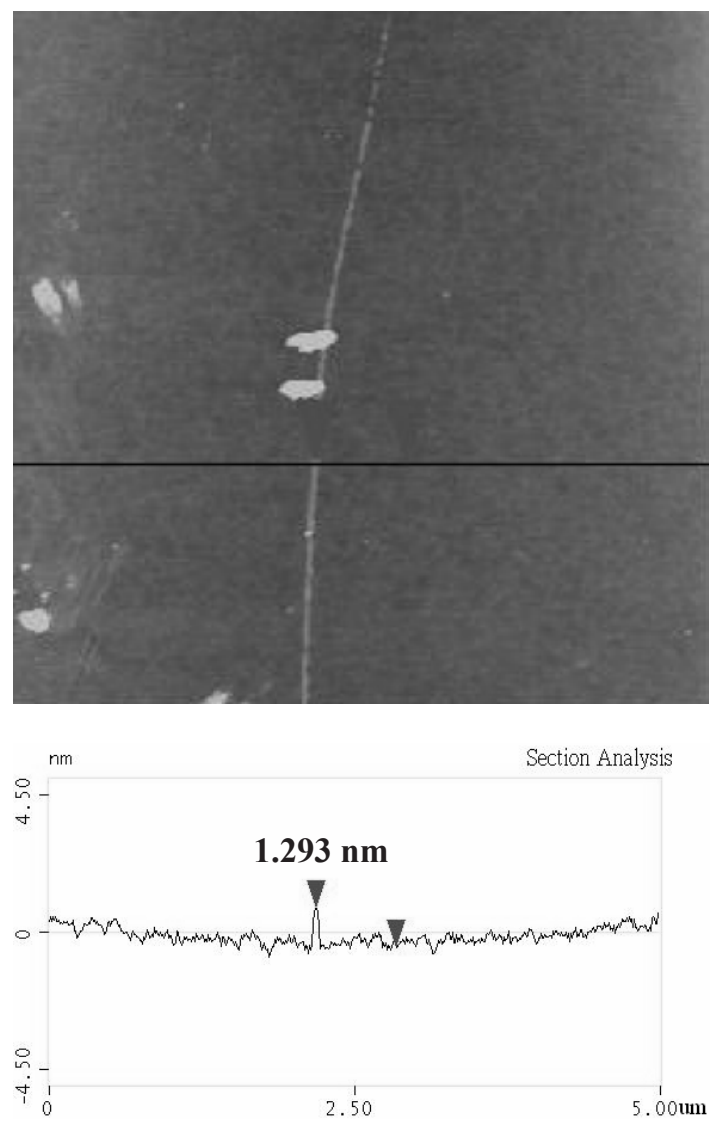

Figure 1.7. The AFM image of SWNT at $700^{\circ} \mathrm{C}$.

SWNTs was synthesized by chemical vapor deposition (CVD) process in a furnace with three different heating regions. The optimal parameters of grown SWNTs in our experiments are shown in Table 1.2.

Table 1.2. The optimal parameters of grown SWNTs at different temperatures.

\begin{tabular}{|l|l|}
\hline Temperature & Optimal parameters \\
\hline $950^{\circ} \mathrm{C}$ & $\begin{array}{l}\mathrm{CH}_{4}: 500 \quad \mathrm{sccm}, \mathrm{H}_{2}: 500 \\
\text { sccm, } \mathrm{C}_{2} \mathrm{H}_{4}: 20 \mathrm{sccm}\end{array}$ \\
\hline $850^{\circ} \mathrm{C}$ & $\begin{array}{l}\mathrm{CH}_{4}: 250 \quad \mathrm{sccm}, \mathrm{H}_{2}: 500 \\
\text { sccm, } \mathrm{C}_{2} \mathrm{H}_{4}: 20 \mathrm{sccm}\end{array}$ \\
\hline $750^{\circ} \mathrm{C}$ & $\begin{array}{l}\mathrm{CH}_{4}: 250 \quad \mathrm{sccm}, \mathrm{H}_{2}: 500 \\
\text { sccm, } \mathrm{C}_{2} \mathrm{H}_{4}: 20 \mathrm{sccm}\end{array}$ \\
\hline $700^{\circ} \mathrm{C}$ & $\mathrm{CH}_{4}: 125 \quad \mathrm{sccm}, \mathrm{H}_{2}: 500$ \\
& $\mathrm{sccm}_{2} \mathrm{C}_{2} \mathrm{H}_{4}: 20 \mathrm{sccm}$ \\
\hline
\end{tabular}

\section{Conclusions}

In summary, experimental results revealed that the reaction gases showed an optimal flow rate at different growth temperatures. The flow rate of methane is important to synthesize SWNTs at low temperature. A higher flow rate of methane would reduce the catalytic activity by the great amount of carbon decomposition at the suitable growth temperature. The flow rate of methane can be reduced by decreasing the growth temperature. We couldn't synthesize SWNTs from ferritin on the substrate at $675^{\circ} \mathrm{C}$. It is possible that the catalyst and carbon source are hard to react at this temperature. In our study, the 
lowest temperature at which a growth of SWNTs by the catalyst of ferritin was observed was $700^{\circ} \mathrm{C}$ and the mean diameter of SWNTs was 1 4 nm.

\section{References}

[1] S. Iijima, 1991, Nature, 354, P.56.

[2] P.M. Ajayan, S. Iilima, 1993, Nature, 361, P.333.

[3] Z. W. Pan, S. S. Xie, B. H. Chang, L. F. Sun, W. Y. Zhou, G. Wang, 1999, Chem. Phys. Lett, 299, P.97.

[4] B. I. Yakobson, R. E. Smalley, 1997, Am. Sci, 85, P.324.
[5] Su. M, Zheng. B, Liu, 2000, J. Chem. Phys. Lett, 322, P.321.

[6] H. E. Unalan, M. Chhowalla, 2005, Nanotechnology, 16, P.2135.

[7] G. H. Jeong, S. Suzuki, 2005, J. App. Phys, 98, P.124311.

[8] Y. Zhang, Y. Li, W. Kim, D. Wang and H. Dai, 2002, Appl. Phys. A, 74, P.325.

[9] D. Kondo, S. Sato, A. Kawabata, Y. Awano, 2005, J. J. Appl. Phys, 44, P.5292.

[10] Yiming Li, Woong Kim, et al., 2001, J. Phys. Chem. B, 105, P. 11424. 